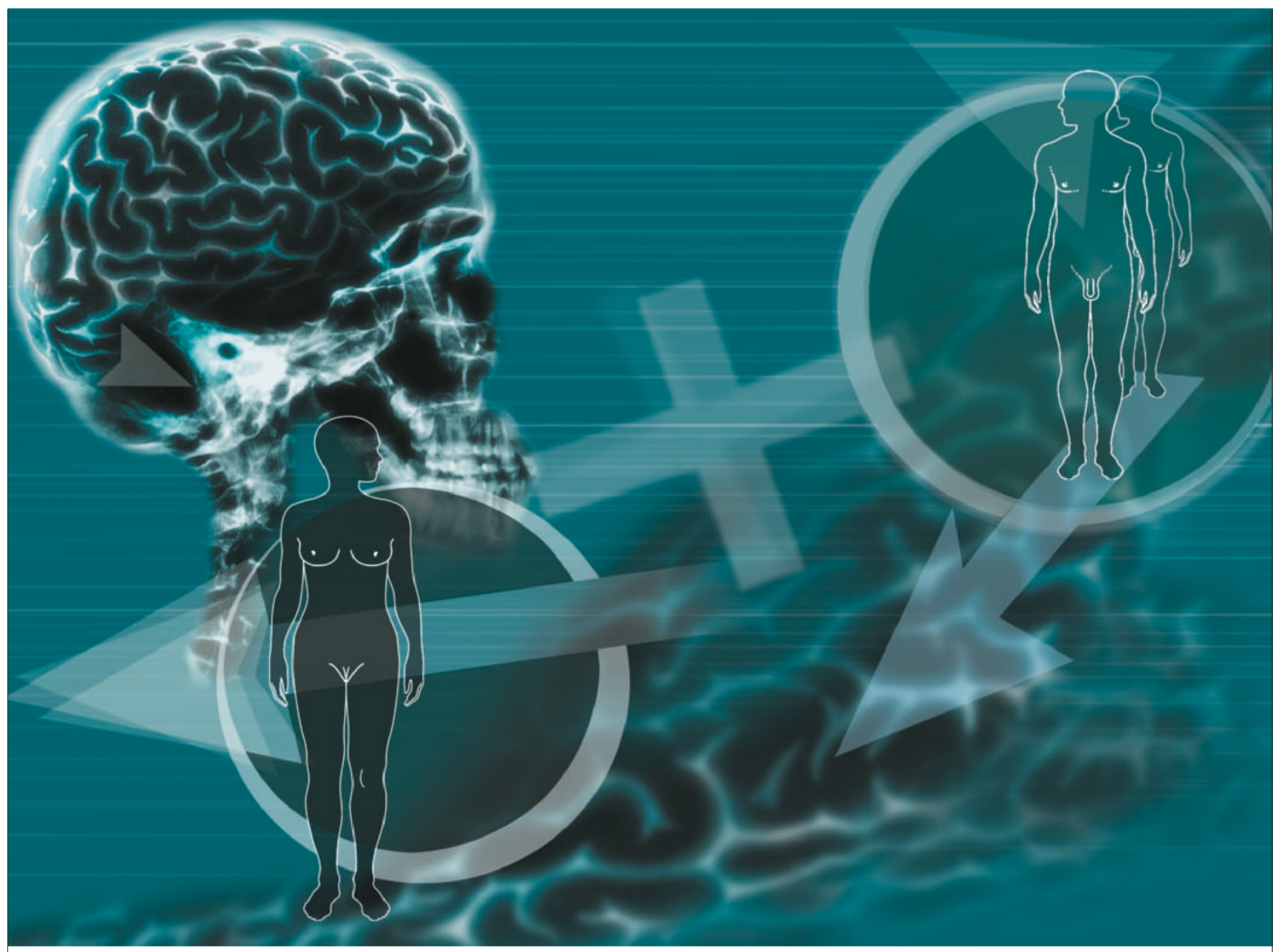

\title{
The most important sexual organ
}

\section{New evidence suggests that the brain begins to develop differently in males and females much earlier than was thought - before sex hormones come into play. Carina Dennis considers the implications.}

0 usan was whisked away as soon as she was born. Her mother wasn't allowed to bathe or undress her for several days; the doctors simply said that there was something wrong. Susan had an 'intersex' condition - her genitalia offered no clear indication whether she was a girl or a boy.

Although Susan is genetically male, doctors convinced her parents that she should undergo surgery to turn her into a girl the operation is easier to perform, and medical opinion was that, with appropriate hormone treatment, she would develop normally in her assigned gender. And so it turned out: Susan is now in her twenties, married and happy as a woman.

But for a small proportion of the one in about 4,000 children born with 'ambiguous' genitalia, things don't work out so well. Tony was also born genetically male and had similar surgery. But he never felt comfortable as a girl. After many years of unhappiness, he began testosterone treatment and now lives as a man.

Susan's and Tony's doctors believed that the brain is a sexual blank slate until it comes under the influence of sex hormones. But biologists are now starting to realize that hormones aren't the only significant determinant of the brain's sexual destiny. Indeed, male and female brains may even start moving down different developmental paths before sex hormones are produced in significant quantities. "There is plenty of evidence that hormones organize the brain sexually, but it's not the whole story," says Eric Vilain, a geneticist at the University of California, Los Angeles (UCLA).

New findings about the genetic and other factors that influence the brain's sexual development could do more than simply rewrite the textbooks. They might provide insights into conditions such as transsexualism - and perhaps eventually lead to tests that could determine whether a baby with an intersex condition is more likely to grow up thinking, feeling and behaving like a man or a woman.

\section{Sex discrimination}

The dogma that hormones are the only important players in the brain's sexual development stems from early experiments showing that castrated male rabbit fetuses seem to develop as females, and newborn female guinea-pigs exposed to testosterone come to look and act like males. These results indicated that the 'default' sex in mammals is female, and suggested that male brain anatomy and behaviour develop as a consequence of exposure to testosterone. 
More recently, geneticists uncovered the 'master switch' that kick-starts the development of the testes in mammals - a gene called Sry on the male-specific Y chromosome ${ }^{1}$. But once this engine is running, testosterone produced by the testes was still assumed to direct the development of male characteristics. And so the idea that the differences between male and female brains are entirely a consequence of their exposure to sex hormones persisted. "The field was completely dominated by hormone people," says Vilain.

The realization that things are rather more complicated comes in part from studies of birds. Their sex chromosomes are different from those in mammals; and in the feathered world, the default pathway for sexual development is male rather than female. But again, the differences between male and female brains were thought to be simply a result of their exposure to sex hormones.

Convincing evidence that this isn't the complete story comes from a rare, naturally occurring zebra finch that was genetically male on the right side of its body, with bright plumage and a testis, and genetically female on the left, with dowdy feathers and an ovary. If brain sex depended solely on hormones, you'd expect both sides of the bird's brain to be the same, as they were both exposed to the same mix of male and female hormones coursing through the blood. But when researchers led by neurobiologist Arthur Arnold at UCLA examined the bird's brain, they found that the neural circuits that control male song were much larger on the right side ${ }^{2}$.

\section{All in the mind}

Manfred Gahr, a neuroscientist at the Free University of Amsterdam in the Netherlands, created his own sexually confused birds. He took Japanese quail embryos and surgically switched their forebrains - which control adult sexual behaviour before their gonads began to develop. If conventional wisdom is correct and sex hormones produced by the gonads do direct the brain's sexual development, then having a forebrain that was genetically the 'wrong' sex should have made no difference to the birds' adult sexual behaviour. And for the females given male forebrains, this was the case: they looked and acted like normal female quail. But the male birds given female forebrains neither crowed to attract mates nor mounted females: their transplanted female brain tissue could not support typical male reproductive behaviour. Their testes also failed to develop normally, indicating that — at least in male quail - a genetically male brain is required to complete the development of the gonads.

It's hard to do similar experiments in mammals, where embryological development occurs in the womb. But Vilain has used DNA microarrays to study gene activity in the brains of male and female mouse embryos from an early stage of development. Of the 12,000 genes active in the brain, 51

of Cancer Research in London. She now plans to compare mice that have been engineered so that Sry is active only in their testes with normal animals in which the gene is expressed in both brain and gonads, looking for any differences in behaviour and brain anatomy.

\section{Under the influence}

Other researchers are also working with mice in which Sry has been manipulated: male mice lacking Sry develop as females, whereas genetically female mice given Sry grow up as males ${ }^{8}$. Using such mice, Arnold teamed up with Ingrid Reisert at the University of Ulm in Germany to investigate a phenomenon that Reisert had identified more than a decade ago: the fact that some cells extracted from the midbrains of male and female embryonic rodents develop differently when grown in culture? ${ }^{9}$. They found that these differences aren't simply a result of Sry kick-starting the production of testosterone in the testes other genes on the sex chromosomes are also apparently involved ${ }^{10}$.

The animals used by Reisert and Arnold were created in the lab of Paul

showed different levels of expression in the brains of male and female mouse embryos before the gonads had formed ${ }^{4}$. This suggests that, in mammals, male and female brains start travelling down different developmental paths from the outset, before hormones have entered the picture.

Whether the genes Vilain has identified have an important biological function in the brain remains unknown. To find out, he is now creating 'knockout' mice in which the genes have been systematically inactivated, to see what effect this has on brain development and sexual behaviour. Initially, Vilain intends to focus on genes on the Y chromosome. "These are obvious candidates," he says.

Other researchers are looking at Sry to determine whether it has a direct influence on the development of the brain, in addition to its role in the testes. The gene certainly seems to be expressed in the brains of male mammals ${ }^{5-7}$, but again, it's unclear what this means. "Expression patterns suggest where genes are acting, but we need functional studies to prove it," cautions Amanda Swain, a developmental biologist at the Chester Beatty Laboratories of the Institute Burgoyne, a developmental biologist at the

develop? UK Medical Research Council's National Institute for Medical Research in London, who has engineered a range of mice with unusual configurations of sex chromosomes. "You name it, we can make it," says Burgoyne, who similarly aims to use the mice to tease out genetic influences on the way in which male and female brains are wired.

Studies of the non-hormonal influences on the sexual development of the mammalian brain are at an early stage. But Vilain is already trying to apply this emerging knowledge to the phenomenon of transsexualism - where individuals are physically and genetically one sex but perceive themselves to be members of the other. Reports of the condition sometimes running in families ${ }^{11}$ have led some researchers to speculate that genetic factors may be involved. "Some of the genes differentially expressed in the brains of male and female mice may be altered in transsexuals,"Vilain suggests.

$\mathrm{He}$ is now collaborating with Vincent Harley, a molecular biologist at Prince Henry's Institute of Medical Research at the Monash Medical Centre in Melbourne, which runs the largest transsexual clinic in Australasia. They are looking for variants in 
the sequence of these genes to see if some are more common in transsexuals than in the general population. Their initial analysis will focus on three genes, located on the sex chromosomes, that are known to encode proteins that regulate the activity of other genes.

Such research into the genetics of gender identity is inevitably controversial - especially given the dark history of the eugenics movement, which viewed conditions such as transsexualism as 'diseases'. But Harley has been overwhelmed by the positive response from the transsexual community since the study began. "I've had people e-mailing me to offer their help," he says. "There is a stigma that transsexualism is a lifestyle choice. It may be very liberating to them if we can show that there is a genetic or biological basis." Indeed, Harley has been invited to give talks about his research to transsexual groups in Melbourne.

\section{Difficult decisions}

Vilain also hopes that this research might result in tests that could help to predict whether a baby with an intersex condition is more likely to grow up feeling like a man or a woman. "Gender is not as simple as $\mathrm{X}$ and Y chromosomes," he says. Many genes are likely to be involved and, if genetic variants associated with the gender that a person feels they belong to can be identified, then it may one day be possible to take a blood sample from a young intersex patient to determine which of these DNA sequences they carry. "If there was a biological tool that could predict the likely gender of a person based on their DNA sequence, that would be very useful for intersex children,"Vilain says.

Babies born with ambiguous genitalia are usually operated on within the first few months of life. "The majority of our patients are satisfied with their assigned gender," says Garry Warne, a paediatric endocrinologist at the Royal Children's Hospital in

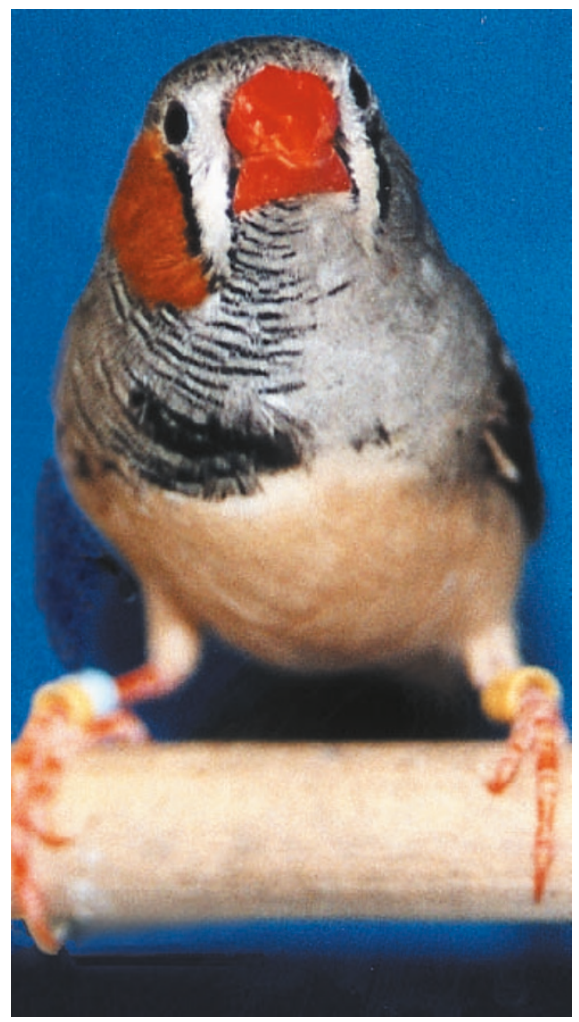

Like its body, this zebra finch's brain was 'male' on the right and 'female' on the left, hinting that more than sex hormones guided its development.

Melbourne, Australia. "In less than $8 \%$ of cases is the outcome bad."

But when the wrong choice is made, as in Tony's case, the consequences are severe. For as long as Tony can remember, he felt like a boy. In his thirties, after voicing his plight on Australian national television, he was finally able to get doctors to provide him with testosterone injections. Not surprisingly, Tony deeply resents the drastic surgery that cast him as a female.

Such distressing experiences lie at the heart of an unresolved debate over when surgery should be used on intersex patients. Tony believes that it should be left until the individual can make an informed decision. But most clinical experts argue that early intervention avoids the psychological damage suffered by a child growing up with ambiguous genitalia. Warne, for instance, has surveyed intersex individuals in Vietnam and India - for whom surgery was not available — and found that most wished they had been operated on as infants.

Given the growing realization that hormones don't act alone in directing the brain to develop along male or female lines, Vilain suggests that any surgery should be delayed until the child can offer consent and has started displaying gender-specific behaviour. But he hopes that it may one day become possible to use genetic tests to allow decisions about gender assignment to be taken with more confidence at an earlier age.

Tony, however, has mixed feelings about the use of genetic information to manage the treatment of intersex patients. "If it can lower the chances of the wrong outcome, that would be fantastic," he says. "But that information shouldn't be used to surgically reinforce one gender."

Carina Dennis is Nature's Australasian correspondent.

1. Koopman, P., Gubbay, J., Vivian, N., Goodfellow, P. \& Lovell-

Badge, R. Nature 351, 117-121 (1991).

2. Agate, R. J. et al. Proc. Natl Acad. Sci. USA 100,

873-4878 (2003).

3. Gahr, M. Proc. Natl Acad. Sci. USA 100, 7959-7964 (2003).

4. Dewing, P., Shi, T., Horvath, S. \& Vilain, E. Mol. Brain Res. 118, 82-90 (2003).

5. Lahr, G. et al. Mol. Brain Res. 33, 179-182 (1995).

6. Mayer, A., Lahr, G., Swaab, D. F., Pilgrim, C. \& Reisert, I. Neurogenetics 1, 281-288 (1998).

7. Mayer, A., Mosler, G., Just, W., Pilgrim, C. \& Reisert, I. Neurogenetics 3, 25-30 (2000).

8. De Vries, G. J. et al. J. Neurosci. 22, 9005-9014 (2002).

9. Beyer, C., Pilgrim, C. \& Reisert, I. J. Neurosci. 11, 1325-1333 (1991).

10. Carruth, L. L., Reisert, I. \& Arnold, A. P. Nature Neurosci. 5, 933-934 (2002).

11. Green, R. Arch. Sex. Behav. 29, 499-507 (2000).
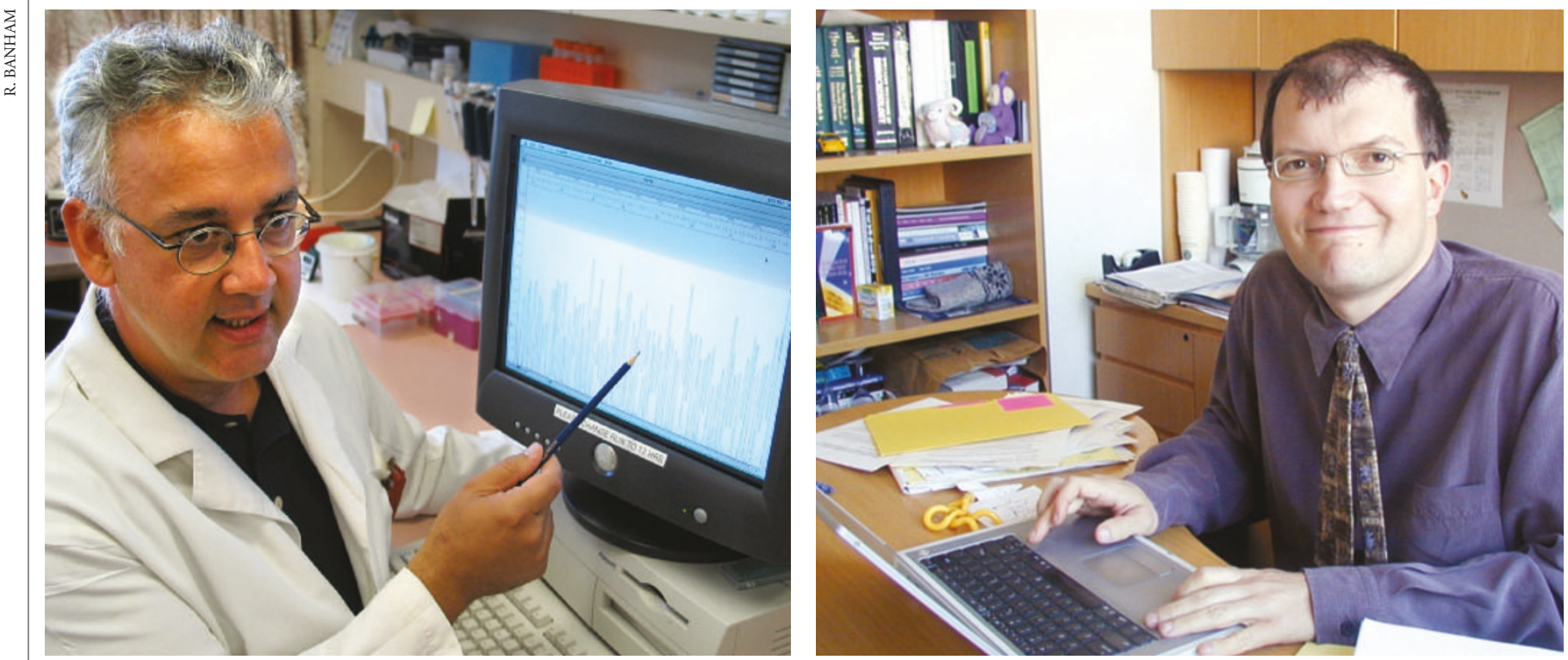

A question of gender: Vincent Harley (left) and Eric Vilain are hoping to find out whether there is a genetic basis for transsexualism. 